\title{
A NEW LITHOGRAPHIC TECHNIQUE FOR THE MANUFACTURE OF HIGH RESOLUTION ZONE PLATES FOR SOFT X-RAYS
}

\author{
M.T. Browne, P. Charalambous, R.E. Burge, P.J. Duke*, A.G. Michette and \\ M.J. Simpson \\ Physics Department, Queen Elizabeth College, University of London, \\ Campden HiZl Road, London W8 $7 \mathrm{AH}, U . K$. \\ * Daresbury Laboratory, Daresbury, Warrington, WA4 $4 A D, U . K$.
}

\begin{abstract}
Résumé - Une technique de lithographie utilisant un microscope électronique à balayage en transmission est en développement. Cette technique est capable de dessiner avec précision sur des petites surfaces, des motifs dont 1 'épaisseur des lignes est inférieure à $50 \mathrm{~nm}$. On décrit la méthode et on discute de ses applications à la fabrication de composants d'optique pour la diffraction des rayons-X mous.
\end{abstract}

Abstract - A 1ithographic technique using a Scanning Transmission Electron Microscope is being developed. This technique is capable of drawing accurate patterns, with line widths much less than $50 \mathrm{~nm}$, over small areas. The method is described and its application to the manufacture of diffractive optical components for soft $\mathrm{X}$-rays is discussed.

\section{Introduction}

One of the major problems in the use of a Scanning Transmission Electron Microscope (STEM) for the study of biological or other material is the build-up of a contamination layer on the specimen surface, causing degradation of the images. Although very high vacuums ( $\leqslant 10^{-7}$ torr) are used, residual gas analyses of the STEM column atmosphere show the presence of, e.g., water vapour, oxygen, nitrogen, and various heavy hydrocarbon molecules. These hydrocarbons, from pumping oils, are the source of the contamination. Brief $1 y$, what happens is as follows. The hydrocarbons form a layer on the surface of the specimen, and are polymerised by the electron beam. Thus they can no longer diffuse, and a build-up of the polymer occurs; if the beam is left in one position a "contamination cone" is formed. Since many electrons pass through the specimen, such cones are formed on both surfaces. Much work has been done to reduce or eliminate this contamination [1], while more recently [2] methods of utilising it have been discussed. In this paper we consider the latter.

\section{Beam Writing}

A Vacuum Generators HB5 STEM has been used for the generation of patterns suitable for use as soft X-ray diffractive optical components. For this purpose, the specimen is replaced by a thin ( $\sim 10-20 \mathrm{~nm})$ carbon film on a standard electron microscope aperture. The films are prepared on mica and floated onto water. The aperture is moved upwards through this and then baked at $\sim 200^{\circ} \mathrm{C}$ for a few minutes to remove remaining water. By scanning the electron beam across the film in a controlled (by microprocessor) way, contamination patterns may be drawn [3]. Due to the limitations of the electron optics, this may only be done accurately over areas with linear dimensions of a few microns ("primary fields"); for larger size patterns the specimen stage must be mechanically scanned and the primary fields joined together ("patched") using appropriate registration marks.

As the hydrocarbons are used up, the contamination rate decreases. To prevent this, a specimen holder incorporating a small oil reservoir has been constructed. The oil and the film are together maintained at $\backsim 100^{\circ} \mathrm{C}$, leading to a high hydrocarbon vapour pressure ( $n 10^{-4}$ torr) in the vicinity of the film (the high temperature also increases the mobility of the hydrocarbon molecules). This results in constant 
replacement (through adsorption) of molecules immobilized by polymerisation, leading to sustained periods of high contamination rate.

The quality of contamination patterns is closely related to both the beam focus and the length of time for which it irradiates any particular point (pixel) of the film. A defocussed beam would create poorly defined lines, while fixed pixel times would result in patterns of uneven thickness due to variations in the contamination rate. The focus problem has been solved by periodically generating a focus-finding scan line, during the course of which the microprocessor minimises the time required for the line spots to reach a certain thickness by changing the focus in $20 \mathrm{~nm}$ steps. The minimum time per pixel corresponds to optimum focus.

The microprocessor is able to detect when each spot has reached the required thickness by constantly monitoring the difference between the dark and bright field signals. The bright field signal decreases with spot thickness while the dark field signal increases. At a particular thickness the two signals are equal, this condition being independent of beam current variations and of the rate of contamination. The starting level of each signal can be individually set to allow the contamination thickness to be controlled.

\section{Manufacture of Linear Diffraction Grating}

To perfect the pattern generation method and to test for distortions a (nominally) $\sim 11 \mu \mathrm{m} \times 30 \mu \mathrm{m}$ linear grating with a pitch of (nominally) $110 \mathrm{~nm}\left(\sim 1.8 \times 10^{4}\right.$ lines/ $\mathrm{mm}$ ) was manufactured. An area of $5 \mu \mathrm{m} \times 5 \mu \mathrm{m}$ was chosen as the primary field, addressable with an accuracy of $2.5 \mathrm{~nm}$. A row of 16 registration 1ines (each $\sim 1.3 \mu \mathrm{m}$ long) was drawn on the first primary field, each 1 ine being accurately registered with respect to the first. The film was then mechanically shifted so that the last line was brought to the position previously occupied by the first, and 15 more lines were drawn, each registered with the new first line. After repeating this process until the row of lines was $\sim 30 \mu \mathrm{m}$ long, the exact position of each line was determined by registering with the first line of the relevant primary field and the line was then extended by about $5 \mu \mathrm{m}$ on either side. Two more lines were then drawn in each of the gaps between the lines. After baking at $\sim 500^{\circ} \mathrm{C}$ for a few minutes to remove excess oil, gold was evaporated onto the film (at an angle to prevent the gaps being filled). The resulting grating is shown in figure 1 - the thick lines perpendicular to the grating structure are for support. Subsequent analysis showed the pitch to be $\sim 125 \mathrm{~nm}(\sim 10 \%$ larger than intended) due to the STEM being poorly calibrated. This, and other effects causing the distortions visible in figure 1 , such as uneven motion of the mechanical stage giving occasionally misplaced lines, have since been corrected. A rotating anode X-ray generator, with a carbon coated anode, was used to obtain a diffraction pattern using the grating (figure 2). Lines due to carbon $K_{\alpha}$, oxygen $K_{\alpha}$ (presumably from the carbon paint stabiliser), and silicon $K_{\alpha}$ (from vacuum grease) can be seen.
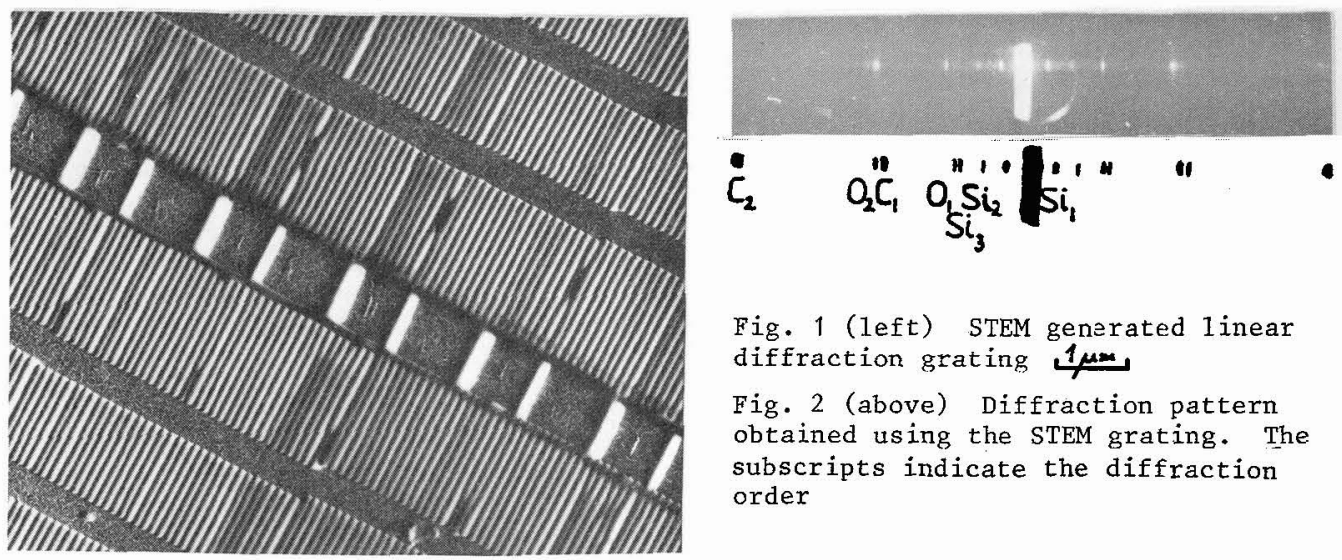

Fig. 1 (left) STEM generated 1inear diffraction grating $1 \mu \mathrm{m}$

Fig. 2 (above) Diffraction pattern obtained using the STEM grating. The subscripts indicate the diffraction order 


\section{Manufacture of Zone Plates}

The first zone plates drawn on the STEM have 100 zones, an outer diameter of $30 \mu \mathrm{m}$ and an outermost zone width of $\$ 5 \mathrm{~nm}$. This is well within the capabilities of the technique, and subsequent zone plates will have much finer zones, and therefore higher resolutions. The zone plates were drawn on carbon films initially coated with a thin layer of contamination (giving a total film thickness of $\sim 20 \mathrm{~nm}$ ) for stability. The pattern was generated in 24 equal angular sectors each containing three primary fields. The sectors were aligned by registration to an accurately drawn inner circle. Each alternate zone was drawn as a series of $\sim 20 \mathrm{~nm}$ wide arcs, each registered with a mark drawn at the inside of the primary field. A visual check was made on the positioning of the zones after every third of an outer primary field, every half of a middle primary field and every inner primary field. This ensured that the zones could be positioned with an accuracy of no worse than $5 \mathrm{~nm}$. After each sector the stage was rotated through $15^{\circ}$ and the process repeated; thus each sector was drawn with the beam in the same region, so that $\mathrm{x}-\mathrm{y}$ distortion was minimised. Since each sector covered an angle of $16^{\circ}$, there was a slight overlap at the ends of the arcs, ensuring a good join. After all the sectors had been drawn, the central zone was filled in (hiding the registration circle and inner registration marks). An example of such a zone plate is shown in figure 3 - the contamination thickness is $\sim 0.15 \mu \mathrm{m}$ and the pattern is uncoated. Methods of coating the patterns with heavy metal layers are currently being investigated.
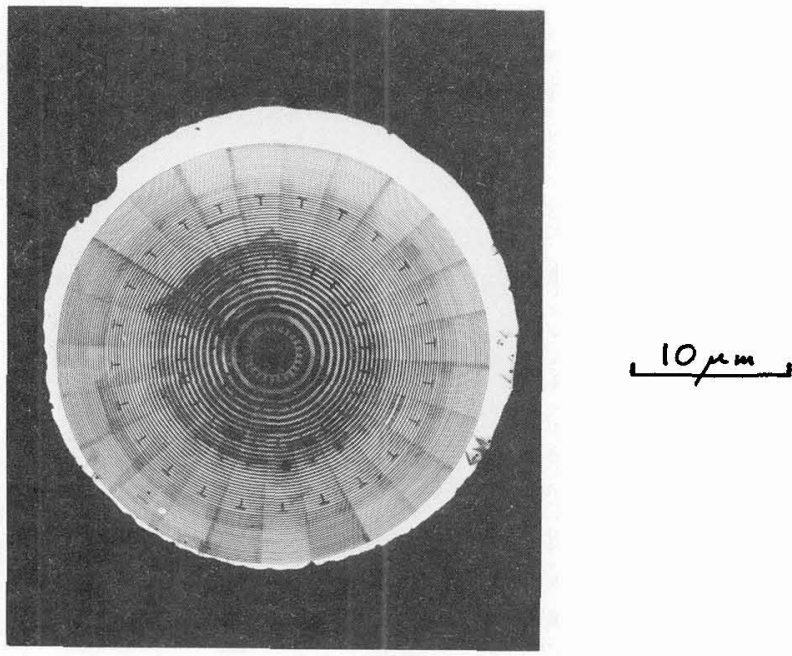

Fig. 3 A STEM generated zone plate, showing registration marks

Further papers in these proceedings will discuss the effects of manufacturing inaccuracies on the imaging properties of STEM generated zone plates [4] and proposed tests of such zone plates in X-ray microscopy [5]. One interesting possibility using such manufacturing methods is to make "composite" zone plates, in which the central zone plate pattern, of first order focal length $f$, is surrounded by further zones whose third order focal length is $f$ (figure 4). This is a way of increasing the resolution (by as much as a factor of 2) and increasing the on-axis focussed intensity (figure 5) when the manufacturing method limits the narrowest line that can be drawn. 


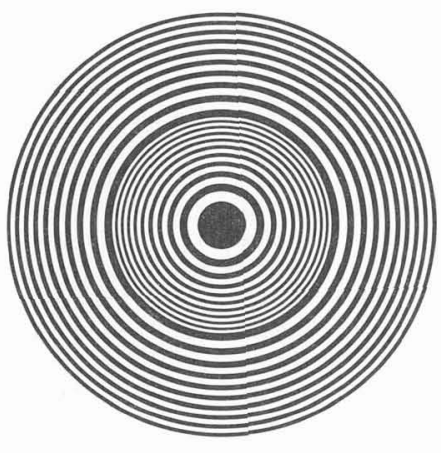

Fig. 4 A composite zone plate

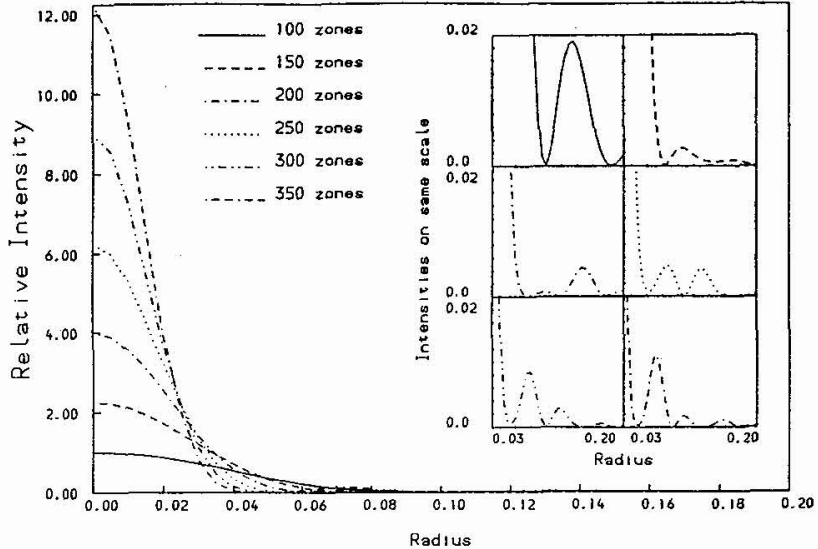

Fig. 5 Intensity distributions for 100 inner zones and various numbers of outer zones

\section{Acknowledgements}

We are grateful to the Science and Engineering Research Council (SERC) for financial support. MJS is supported by an SERC grant.

\section{References}

[1] See, e.g., REIMER L., and WACHTER M., U1tramicroscopy 3 (1978) 169-174. HARADA V., TOMTTA T., and WATABE T., Scanning Electron Microscopy II (1979) 103-110.

[2] BROERS A.N., CUOMO J., HARPER J., MOLZEN W., LAIBOWITZ R., and POMERANTS M., Ninth International Congress on Electron Microscopy, Toronto vol. III (1978) 343-354.

[3] BROWNE M.T., ChARALAMbOUS P., and BURGE R.E., Inst. Phys. Conf. Ser. 61 (1982) 43-44.

[4] SIMPSON M.J., BROWNE M.T., BURGE R.E., CHARALAMBOUS P., DUKE P.J. and MTCHETTE A.G. These proceedings $p$.

[5] BURGE R.E., DUKE P.J., MacDOWELl A., MICHETTE A.G., MILlER A., ROSSER R., STMPSON M., and WEST J.B. These proceedings p. 